\title{
Ants Response to Human-Induced Disturbance in a Rain Tropical Forest
}

\author{
B Walter, A Graclik, P Tryjanowski, O Wasielewski \\ Institute of Zoology, Poznan Univ of Life Sciences, Poznan, Poland
}

\section{Keywords}

Ants, biodiversity loss, colony size, deforestation, Platythyrea punctata tropical rain forest

\section{Correspondence \\ O Wasielewski, Institute of Zoology, Poznan Univ of Life Sciences, Wojska Polskiego 71 C, 60-625 Poznan, Poland; oskarw@au. poznan.pl}

Edited by Marcelo N Rossi - UNIFESP

Received 30 November 2017 and accepted 13 July 2018

Published online: 23 August 2018

(C) The Author(s) 2018

\begin{abstract}
A high rate of human-induced disturbance of tropical ecosystems results in enormous loss of biodiversity due to local extinctions. Yet, mechanisms at the population level that lead to the extinction are still poorly understood. Here we tested the hypothesis that human-induced disturbance results in smaller amount of nesting sites for wood-dwelling arthropods that leads to smaller population size and diminished reproduction, and therefore, may promote local extinctions. We completed censuses in less-disturbed and human-disturbed secondary rain forest plots in Puerto Rico. We measured population size and brood production in wood-nesting ants and examined whether these parameters differ between less-disturbed and more-disturbed habitats. In addition, we measured volume of wood parts of all inhabited and potential nesting sites to assess nest site availability. We found that more human-disturbed forests furnish smaller nest sites, resulting in diminished population size and lowered brood production. Our study shows that human-induced disturbance decreases volume of available nesting sites that leads to decreased population size and lowered reproduction. Thus, in addition to the well-documented loss of species richness in human-disturbed tropical habitats, we demonstrated the direct effect of the disturbance that may promote vulnerability of local populations.
\end{abstract}

\section{Introduction}

Tropical rain forests are the most complex ecosystems and host the highest number of species on Earth (Myers et al 2000, Brooks et al 2006, Gibson et al 2011). Unfortunately, the last four decades were marked by an enormous scale of deforestation caused by human activity (Skole \& Tucker 1993, Achard et al 2002, Primack \& Corlet 2005). Although vegetation often forms secondary rain forest on previously deforested areas (Achard et al 2002, Chazdon 2008), such human-disturbed habitats are characterized by substantially diminished biodiversity, as compared with primary forest (Bradshaw et al 2008, Chazdon 2008, Gardner et al 2008). The impoverished biodiversity of disturbed habitats is linked directly to simplified structural complexity and loss of resources, and as a consequence, indirectly to changes in microclimate and habitat availability (Tews et al 2004, Klimes et al 2012). Although the effect of human-induced disturbance on species richness has already been documented in various plant and animal taxa (Roth et al 1994, Kalif et al 2001, Dunn 2004), little is known about how the human disturbance influences reproduction and population size of species, which may lead to local extinction, resulting in the lower biodiversity of disturbed tropical forests (Furrer \& Pasinelli 2016, Alroy 2017). One of the major indicators of tropical biodiversity are ants, constituting up to $85 \%$ of animal biomass in tropical rain forest canopy (Holldobler \& Wilson 1990, Floren \& Linsenmair 1997, Davidson et al 2003). Following the general trends, ant species richness is substantially impoverished in habitats disturbed by human activity (Kalif et al 2001, Klimes et al 2012). Although the lower ant species number may result from a reduced 
availability of nest sites in human-disturbed secondary forests (Shulz \& Wagner 2002, Armbrecht et al 2004, Philpott \& Foster 2005, Powell et al 2011, Klimes et al 2012, Yanoviak et al 2012), the direct response of insect populations to human-induced disturbance that promotes local extinction is still poorly understood (Zmichorski 2011, Santos 2016). Forest disturbance may reduce nest site availability because during forest cutting in tropics, litter and organic matter are immediately destroyed (Lohbeck et al 2015, da Silva et al 2017). The disturbance may lead to diminished size of population and individuals or colonies that results in impoverished brood production. Similar effect of the human disturbance was found in neotropical dung beetles for which human activity leads to decrease population size and lower individual body mass (Gardner et al 2008). In addition, we expected for social insects that the disturbance will result in a smaller colony size. In social insects, brood productivity is strictly linked with colony size: larger colonies produce larger brood number and larger proportion of sexual brood that later may establish new colonies (e.g., Walter et al 2011, Luque et al 2013, DiRienzo \& Dornhaus 2017). Therefore, the predicted smaller colony size may lead to lower brood production resulting in lower viability of populations in more-disturbed locations. In this study, we examined direct mechanisms that affect colony architecture (size, composition, and productivity) of the neotropical ponerine ant Platythyrea punctata (Smith 1858) (Fig 1a) by comparing populations from habitats with different degrees of disturbance: less-disturbed mature rain forest versus populations from recently more-human-disturbed rain forest in Puerto Rico (Fig 1 b, c). This ant species provides an ideal model to study the effect of habitat change on population parameters, as $P$. punctata occurs both in natural and in disturbed habitats distributed over West Indies and Central American mainland (Seal et al 2011). Similar to most of tropical ant species and many other arthropods, the ant $P$. punctata inhabits nest sites inside dead, dry, and soft wood such as twigs, branches, or trunks previously hollowed by bark beetles (Fig 1d; Schilder et al 1999, Seal et al 2011). Thus, $P$. punctata, like many other tropical arthropods nesting almost exclusively inside wood, is sensitive to humaninduced disturbance that removes wood from a habitat, such as logging or clear-cutting. Therefore, we tested hypotheses that (1) colonies from more-disturbed habitats are characterized by smaller size and lower brood production than colonies from undisturbed habitats and (2) differences in colony size and brood production between colonies from less-disturbed and more-disturbed habitats are associated with differences in nest site availability. We indicated the direct mechanism that weakens population structure such as size and reproduction and promotes local extinctions and, as a consequence, biodiversity loss in disturbed locations.

\section{Material and Methods}

\section{Less-disturbed and more-disturbed habitats}

Colonies of the neotropical ponerine ant $P$. punctata were collected in Puerto Rico, West Indies, in the middle of the rain season in August 2011 (Table 1). After collecting, ants were transported to laboratories for detailed studies on their behavior. The distance between study sites was more than $5 \mathrm{~km}$. Firstly, we chose eight plots, 0.25 ha each, in secondary Caribbean hurricane rain forest at El Yunque National Forest that were formerly used as a coffee plantation and have been for natural succession and protected since 1934. The plots at El Yunque National Forest served us as an example of locations without recent human-induced disturbance. As examples of more-disturbed habitats, we chose nine locations across the island, covered by secondary tropical rain forests (Helmer et al 2002), where larger trees are removed by logging or are absent due to recent land use for agriculture. The data about recent land-use history were collected from aerial and satellite photos. Vegetation status and type of current human-induced disturbance (i.e., clear-cut or selective logging) were checked during site visits in years 2005 and 2011. Previous studies documented that the populations from examined locations exhibit the same reproduction mode (Kellner \& Heinze 2011, Kellner et al 2013), i.e., in both types of habitat in Puerto Rico, the P. punctata ants reproduce via thelytokous parthenogenesis. Therefore, the differences between populations from less-disturbed and moredisturbed habitats in colony size, brood reproduction, and genetic structure should result from other factors than mode of reproduction.

\section{Colony identification, size, and composition}

To identify all colonies from a particular plot, we examined available nest site, such as dead hollowed wood (twigs, branches, logs, trunks) and exceptionally rolled leaves. Although such a direct searching procedure (Bestelmeyer \& Casanova 2010) is labor-intensive, it allows to detect nearly all colonies in the study area, regardless of vegetation density. In addition, foragers coming back to the nest with pieces of food were followed. Except for two colonies that were spotted during migration, all colonies in study locations inhabited chambers inside dead and dry hollowed wood. In order to identify the exact colony size (worker number) and number of brood, we gently placed every piece of wood with a nest of $P$. punctata in a plastic box $(100 \mathrm{~cm}$ long, $50 \mathrm{~cm}$ wide, and $25 \mathrm{~cm}$ high) with wall edges treated with paraffin oil that prevented ants from escaping. Then we carefully split wood inside the box into $\sim 0.5-\mathrm{cm}^{3}$ cubes with a pocket knife, removed wood piece by piece, and transferred all ants and their brood from the box to Falcon vials using an aspirator. 

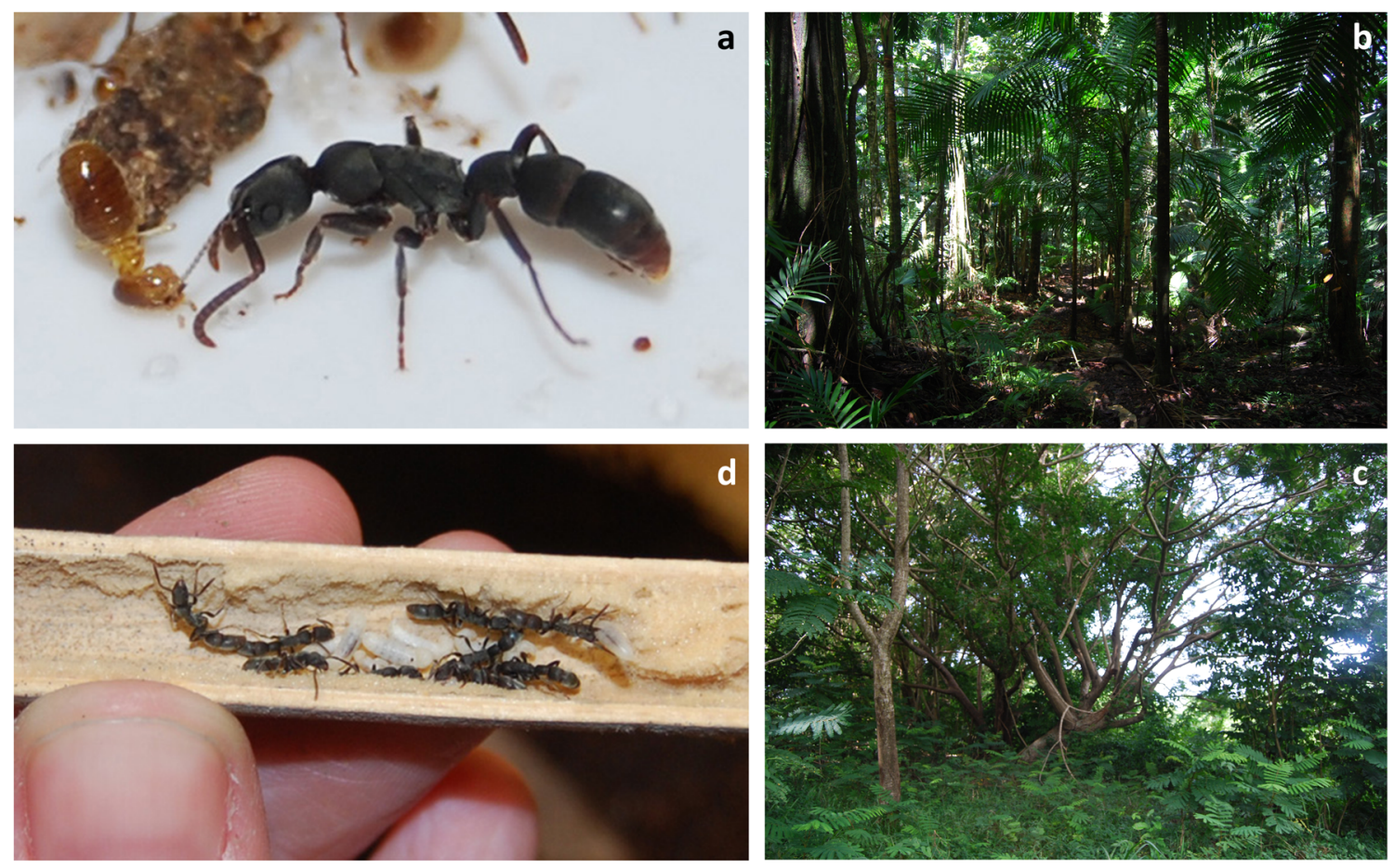

Fig 1 Tropical rain forests in the Caribbean: less disturbed (B) and more disturbed (C) by human activity. More-disturbed forests furnish smaller wood pieces, such as logs or branches, which results in smaller size of nesting sites (e.g., artificial laboratory nest similar to the natural) (D) and directly leads to diminished population size and lower brood production in wood-nesting Platythyrea punctata ants (A).

After collecting ants from a nest, we waited two additional hours for individuals that were foraging at the time when we removed the nest. Such foragers circulating around the original position of a nest and carrying dead insects were collected. All foragers came back to the nest within one hour, suggesting that our two-hour procedure was sufficient. When all individuals from a single nest were collected, we assessed colony size (number of fully colored workers with black cuticle) and number of brood (larvae, pupae, and freshly eclosed callow workers, distinguished by their pale cuticle).

\section{Size of inhabited and uninhabited wood}

Before wood with a nest site was split to collect a colony, we measured wood length $(I)$ and diameter $(d)$. Wood size with nest site was calculated as a cylinder with volume defined as $V=\pi(2-1 d) 2$. In addition, we measured the volume of uninhabited wood in both less-disturbed and more-disturbed habitats in order to test whether the size of available wood with potential nest sites differs between the habitats. To test these differences, we collected all wood pieces of dry hard

Table 1 Location and differences in number of colonies and individuals between two habitats: less and more disturbed.

\begin{tabular}{llllll}
\hline Location & Type of habitat & $\begin{array}{l}\text { Examined } \\
\text { area [ha] }\end{array}$ & $\begin{array}{l}\text { Number } \\
\text { of colonies }\end{array}$ & $\begin{array}{l}\text { Number of colony } \\
\text { per } 0.25 \text { ha }\end{array}$ & $\begin{array}{l}\text { Number of individuals } \\
\text { per colony }\end{array}$ \\
\hline El Verde* & Less disturbed & 3.86 & 10 & 0.65 & 79 \\
El Tunel & More disturbed & 0.24 & 3 & 3.16 & 35 \\
Juncos & More disturbed & 0.28 & 6 & 5.29 & 36 \\
Liquillo & More disturbed & 0.90 & 18 & 5.00 & 29 \\
Parcelas Vieques & More disturbed & 1.80 & 10 & 1.39 & 38 \\
Pico & More disturbed & 1.57 & 11 & 1.75 & 24 \\
Pitahaya & More disturbed & 0.08 & 1 & 3.33 & 46 \\
Sabana & More disturbed & 0.27 & 5 & 4.61 & 26 \\
Yuquiyu & More disturbed & 0.39 & 4 & 2.58 & 1.34 \\
Yuquiyu II & More disturbed & 0.37 & 2 & 19 \\
\hline
\end{tabular}

*But on this area for more detailed studies were chosen 8 plots each 0.25 by size. 
wood with cavities bored by other insects. Therefore, the wood that was not inhabited by the ant $P$. punctata was collected from the same plots (described above) that served for collecting ants in less-disturbed and more-disturbed habitats. And for the further analyses, we chose only dry and hard wood with cavities bored by other insects.

\section{Statistical analyses}

All studied variables deviated significantly from normal distribution (Kolmogorov-Smirnov test, $K$ - $S>1.41$ and $P<0.04$ in all analyses); therefore, data used in Multiple General Model were log transformed in SPSS 21.0 (according to the function $\log _{10}+1$, because of $O$ in a few cases) and after transformation followed normal distribution (KolmogorovSmirnov test, $K-S<1.24$ and $P>0.09$ in all analyses). In other cases, to compare two studied main habitats, the more conservative nonparametric Mann-Whitney $U$ test was used. Therefore, the data in comparative analyses were presented as real values, i.e., were not $\log _{10}$ transformed.

\section{Results}

Colonies collected in more-disturbed habitats were on average threefold smaller (Fig 2a, Mann-Whitney $U$ test: $U=$ 90.0, $Z=-4.08 ; P<0.0001$ ) and had twofold less larvae than colonies from undisturbed habitat (Fig 2b, Mann-Whitney $U$ test: $U=195.5, Z=-2.49, P=0.013$ ). Larger colony size in the population inhabiting undisturbed habitat can be most likely explained by substantially larger size of nest sites that are available in undisturbed locations. Uninhabited wood with potential nest sites was on average fourfold larger in undisturbed forests than in disturbed forests (Fig 3a, MannWhitney $U$ test: $U=121.0, Z=2.97, P<0.004)$.
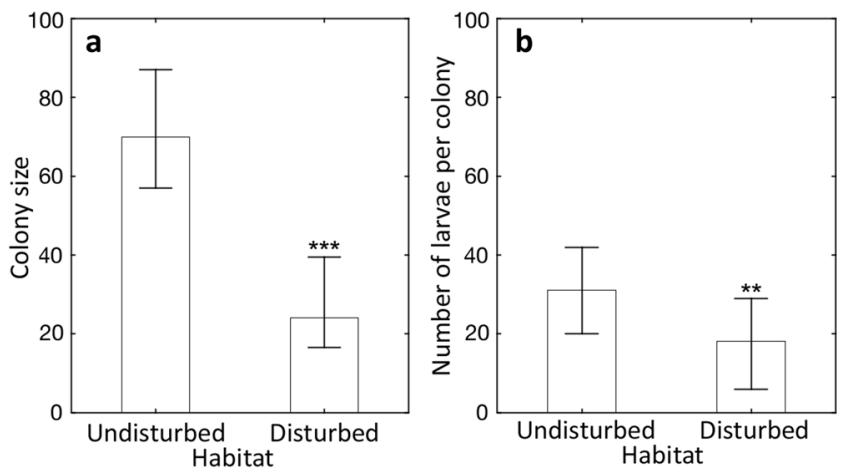

Fig 2 A, B Colony size (worker number) and number of larvae per colony of the neotropical ponerine ant Platythyrea punctata from undisturbed (less disturbed) and human-disturbed (more disturbed) rain forests in Puerto Rico. Columns represent median values; whiskers indicate upper and lower quartiles. Mann-Whitney $U$ test: ${ }^{* * *} P<0.0001 ; * * P=0.013$ (less disturbed $n=17$; more disturbed $n=30$ ).
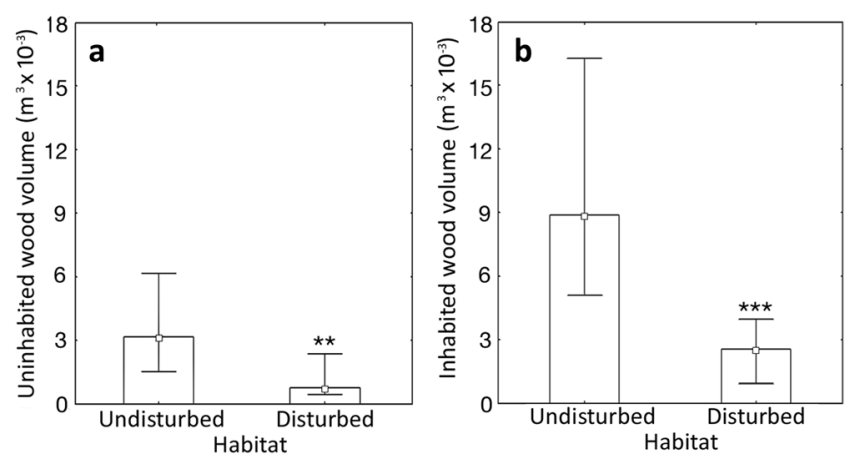

Fig 3 Size of favorable ant nest sites (i.e., dry and hard wood pieces) in undisturbed (less disturbed) and human-disturbed (more disturbed) rain forests in Puerto Rico: A volume of wood with cavities not occupied by the Neotropical ponerine ant Platythyrea punctata. B Volume of wood occupied by the ants. Columns represent median values; whiskers

Consequently, colonies from less-disturbed forests inhabited on average significantly larger wood pieces than colonies from more-disturbed habitats (Fig $3 \mathrm{~b}$, Mann-Whitney $U$ test: $U=81.5, Z=3.51, P<0.001)$. As predicted, there was a positive significant correlation between nest site size and colony size $(r=0.322, P=0.014)$ and in the model taking into account both the effect of habitat type (less disturbed vs. more disturbed) and the effect of nest site size; only the effect of habitat was significant (regression analyses: habitat effect $B=-43.3 \pm 10.1, P<0.0001$; nest size $\log$ volume $B=8.3 \pm$ 10.7, $P=0.44$; interaction between factors $P=0.78$ ). We observed that in both less-disturbed and more-disturbed forests, the ant $P$. punctata prefers to nest in hard and dry wood ( $81 \%$ of colonies) rather than soft and wet wood (19\% of colonies). These habitat preferences (wood with appropriate size and favorable dryness and hardness (Parr 2012) make

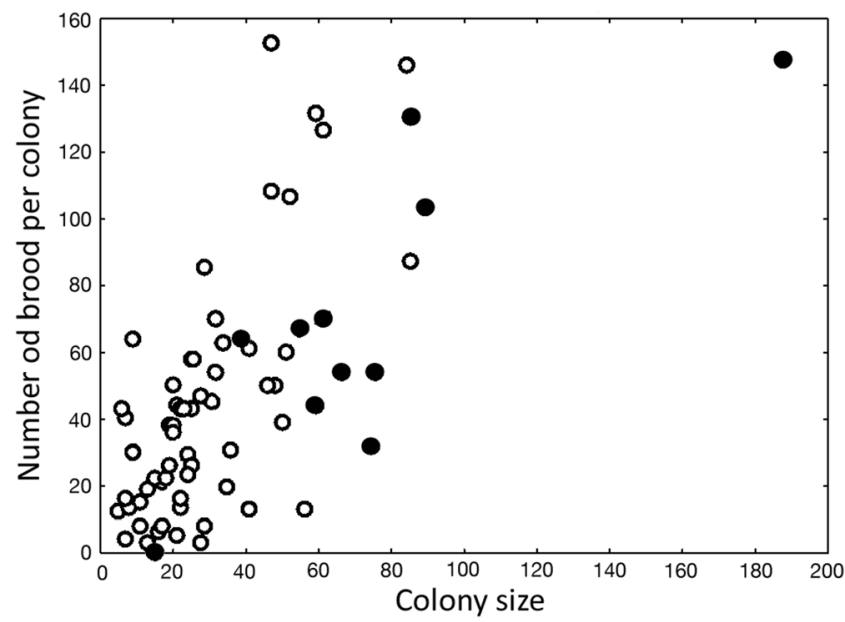

Fig 4 Colony size (worker number) and brood production (sum of larvae, pupae, and freshly eclosed callow workers) in the Neotropical ponerine ant Platythyrea punctata from less-disturbed (black circle) and more-human-disturbed (white circle) rain forests in Puerto Rico. Spearman rank order correlation: $n=70, r_{s}=0.67, t(n-2)=7.36$, $P<0.00001$. 
the available nest sites for this ant species scarcer. Furthermore, colonies from less-disturbed forests produced significantly more brood than colonies from more-disturbed forests (Mann-Whitney $U$ test: $U=181.0, Z=-2.32, P=$ 0.021). That was most likely due to larger colony size in less-disturbed forests, as we observed a positive correlation between colony size and overall brood production (sum of number of larvae, pupae, and freshly eclosed callow workers) in both habitat types (Fig 4), for less-disturbed and moredisturbed forests: $r s=0.620, P=0.042$, and $r s=0.588$, $P<0.0001$, respectively).

\section{Discussion}

Our study demonstrates that even species that can adapt to disturbed conditions suffer from diminished colony size and decreased brood production due to human-induced disturbance. Furthermore, it should consider the possibility of hindered factor such as general reduction of habitat productivity producing smaller wood pieces and fewer food sources for ant colonies. In more-disturbed forests, ants formed threefold smaller colonies (Fig 2a) than in less-disturbed locations, most likely due to a lack of suitable nest sites for large colonies (Fig 3) as indicated by our multi-regression model. Large colonies of $P$. punctata in all of the study locations were found in large pieces of hard and dry wood for nesting, which are absent in more-disturbed habitats (Fig 3). Thus, disturbance of rain forest leads to reduction of nest site size, resulting in reduced colony size. Such decreased colony size in disturbed locations correlates with diminished brood production as number of produced brood is proportional to colony size (Fig 4). Smaller colony size can decrease colony survival (Johnson 2004) and, along with lower brood production, may increase the probability of species extinction in human-disturbed habitats due to stochastic events, such as hurricanes. Therefore, reduction of nest site size in disturbed habitats, which leads to diminished colony size and lower brood production, can be a mechanistic explanation why, in consequence, species number decreases in human-disturbed tropical forests. Indeed, in our study locations, the smaller size of wood piece inhabited by an average ant colony may provide less-convenient shelter and poorer protection against rain or larger predators, such as Puerto Rican Woodpecker (Melanerpes portoricensis), and therefore lead to lower colony survival in more-disturbed habitats. Moreover, smaller colony size weakens populations in disturbed habitats further due to diminished brood production in small colonies. Indeed, small colonies that were typical for more-disturbed locations produced significantly less brood than colonies from less-disturbed locations (Fig $2 \mathrm{~b}$ ). Alternatively, less large nest sites but many small sites in the more-disturbed area may result in a larger number of colonies and overall a large population size even if the average colony size is smaller. That most likely makes colonies from disturbed habitats even more prone to local extinction as low brood production decreases their ability to stabilize or increase the number of colonies in next generations. Our results concur with previous observations in other social insects that small colonies produce less (Luque et al 2013) or even any sexual brood (Walter et al 2011). Our field observations are also consistent with results of a laboratory experiment (Hartmann et al 2003) where P. punctata colonies with experimentally added larger number of larvae, but otherwise with size similar to that found in our disturbed habitats, were not able to rear surplus brood. We documented that a large size of hollowed wood, along with high hardness and low moisture, make a wood piece more favorable for colonization. Thus, habitat disturbance, caused by removal of large trees from a plot by logging or clear-cutting, leads to further reduction of potential nest sites, as hard and dry wood is already limited in rain forest due to high rainfall and high decomposition rate. Effect of both size and other characteristics of wood inhabited by the ants supports the hypothesis that availability of nest sites influences ant colony size in disturbed rain forest. Our results concur with studies indicating the importance of availability of nest sites for animal biodiversity (Tews et al 2004) and ants in particular (Schulz \& Wagner 2002, Powell et al 2011 Klimes et al 2012, Yanoviak et al 2012, Michlewicz \& Tryjanowski 2017).

In conclusion, the results indicate that human-induced disturbance results in reduced average size of available nest sites in tropical rain forests, and that leads to significantly diminished ant colony size and brood production. The smaller population size and lessened reproduction likely makes populations inhabiting disturbed habitats more vulnerable to extinction than populations inhabiting undisturbed habitats. Thus, in addition to the well-documented loss of species richness in human-disturbed tropical habitats (Tews et al 2004, Klimes et al 2012), we demonstrated the direct effect of the disturbance that may promote vulnerability of local populations. That emphasizes importance of protection of undisturbed tropical rain forests and provides further argument for their comprehensive protection (Myers et al 2000, Brooks et al 2006, Gibson et al 2011).We hope that our study will encourage scientists worldwide to study factors that promote extinction of local animal populations in habitats disturbed by human activity.

Acknowledgments We thank the USDA Forest Service for providing BW with collecting permit at El Yunque National Forest (EYNF; CNF2113), Alonso Ramirez for the land-use history of collecting sites at EYNF, and Francisco Perez for the kind hosting at El Verde Field Station. Colonies outside EYNF were collected on private properties and we thank all landowners for their support and help. We are grateful to Madeleine Beekman, Milan Janda, Dawid Moroń, and Sylwia Ufnalska, who read the early versions of the manuscript and provided us with helpful comments. 
Electronic supplementary material The online version of this article (https://doi.org/10.1007/s13744-018-0624-5) contains supplementary material, which is available to authorized users.

Funding information This project was supported by the National Science Centre Poland (N N304 294240).

Open Access This article is distributed under the terms of the Creative Commons Attribution 4.0 International License (http://creativecommons.org/licenses/by/4.0/), which permits unrestricted use, distribution, and reproduction in any medium, provided you give appropriate credit to the original author(s) and the source, provide a link to the Creative Commons license, and indicate if changes were made.

\section{References}

Achard F, Eva HD, Stibig HJ, Mayaux P, Gallego J, Richards T, Malingreau JP (2002) Determination of deforestation rates of the world's humid tropical forests. Science 297:999-1002

Alroy J (2017) Effects of habitat disturbance on tropical forest biodiversity. PNAS 114:6056-6061

Armbrecht I, Perfecto I, Vandermeer J (2004) Enigmatic biodiversity correlations: ant -diversity responds to diverse resources. Science 304:284-286

Bestelmeyer B, Rio Casanova $L$ (2010) Field techniques for sampling ants. In: Lach L, Parr KL, Abbott CL (eds) Ant ecology. Oxford University Press, Oxford, pp 39-41

Bradshaw CJ, Sodhi NS, Brook BW (2008) Tropical turmoil: a biodiversity tragedy in progress. Front Ecol Environ 7:79-87

Brooks TM, Mittermeier RA, da Fonseca GA, Gerlach J, Hoffmann M, Lamoreux JF, Mittermeier CG, Pilgrim JD, Rodrigues ASL (2006) Global biodiversity conservation priorities. Science 313:58-61

Chazdon RL (2008) Beyond deforestation: restoring forests and ecosystem services on degraded lands. Science 320:1458-1460

da Silva NM, Angeoletto F, Santos JW, Paranhos Filho AC, Vacchiano MC, Bohrer JF, Cândido AKA (2017) The negative influences of the new Brazilian forest code on the conservation of riparian forests. Eur J Ecol 3:116-122

Davidson DW, Cook SC, Snelling RR, Chua TH (2003) Explaining the abundance of ants in lowland tropical rainforest canopies. Science 300:969-972

DiRienzo N, Dornhaus A (2017) Temnothorax rugatulus ant colonies consistently vary in nest structure across time and context. PLoS One 12(6):e0177598

Dunn RR (2004) Managing the tropical landscape: a comparison of the effects of logging and forest conversion to agriculture on ants, birds, and Lepidoptera. Forest Ecol Manag 191:215-224

Floren A, Linsenmair KE (1997) Diversity and recolonisation dynamics of selected arthropod groups on different tree species in a lowland rain forest in Sabah, Malaysia with special reference to Formicidae. In: Stork NE, Adis J, Didham RK (eds) Canopy arthropods. Canopy arthropods. Chapman \& Hall, London, pp 344-381

Furrer RD, Pasinelli G (2016) Empirical evidence for source-sink populations: a review on occurrence, assessments and implications. Biol Rev 91:782-795

Gardner TA, Hernandez MI, Barlow J, Peres CA (2008) Understanding the biodiversity consequences of habitat change: the value of secondary and plantation forests for Neotropical dung beetles. J Appl Ecol 45:883-893

Gibson L, Lee TM, Koh LP, Brook BW, Gardner TA, Barlow J, Peres CA, Bradshaw CJA, Laurance WF, Lovejoy TE, Sodhi NS (2011) Primary forests are irreplaceable for sustaining tropical biodiversity. Nature 478:378-381
Hartmann A, Wantia J, Torres JA, Heinze J (2003) Worker policing without genetic conflicts in a clonal ant. Proc Natl Acad Sci U S A 100: 12836-12840

Helmer EH, Ramos O, del M Lopez T, Quinonez M, Diaz W (2002) Mapping the forest type and land cover of Puerto Rico, a component of the Caribbean biodiversity hotspot. Caribb J Sci 38:165-183

Holldobler B, Wilson EO (1990) The ants. Belknap Press, Cambridge, MA

Johnson RA (2004) Colony founding by pleometrosis in the semiclaustral seed harvester ant Pogonomyrmex californicus (Hymenoptera: Formicidae). Anim Behav 68:1189-1200

Kalif KA, Azevedo-Ramos C, Moutinho P, Malcher SA (2001) The effect of logging on the ground-foraging ant community in eastern Amazonia. Stud Neotrop Fauna E 36:215-219

Kellner K, Heinze J (2011) Mechanism of facultative parthenogenesis in the ant Platythyrea punctata. Evol Ecol 25:77-89

Kellner K, Seal J, Heinze J (2013) Sex at the margins: parthenogenesis vs. facultative and obligate sex in a Neotropical ant. J Evol Biol 26:108-117

Klimes P, Idigel C, Rimandai M, Fayle TM, Janda M, Weiblen GD, Novotny V (2012) Why are there more arboreal ant species in primary than in secondary tropical forests? J Anim Ecol 81:1103-1112

Lohbeck M, Poorter L, Martínez-Ramos M, Bongers F (2015) Biomass is the main driver of changes in ecosystem process rates during tropical forest succession. Ecology 96:1242-1252

Luque GM, Giraud T, Courchamp F (2013) Allele effects in ants. J Anim Ecol 82:956-965

Michlewicz M, Tryjanowski P (2017) Anthropogenic waste products as preferred nest sites for Myrmica rubra (L.) (Hymenoptera, Formicidae). J Hymenopt Res 57:103-114

Myers N, Mittermeier RA, Mittermeier CG, da Fonseca GA, Kent J (2000) Biodiversity hotspots for conservation priorities. Nature 403:853-858

Parr CL (2012) Unpacking the impoverished nature of secondary forests. J Anim Ecol 81:937-939

Philpott SM, Foster PF (2005) Nest-site limitation in coffee agroecosystems: artificial nests maintain diversity of arboreal ants. Ecol Appl 15: 1478-1485

Powell S, Costa AN, Lopes CT, Vasconcelos HL (2011) Canopy connectivity and the availability of diverse nesting resources affect species coexistence in arboreal ants. J Anim Ecol 80:352-360

Primack RB, Corlett R (2005) Tropical rain forests: an ecological and biogeographical comparison. Blackwell Science Ltd, Oxford

Roth DS, Perfecto I, Rathcke B (1994) The effects of management systems on ground-foraging ant diversity in Costa Rica. Ecol Appl 4:423-436

Schilder K, Heinze J, Holldobler B (1999) Colony structure and reproduction in the thelytokous parthenogenetic ant Platythyrea punctata (F. Smith) (Hymenoptera, Formicidae). Insect Soc 46:150-158

Schulz A, Wagner T (2002) Influence of forest type and tree species on canopy ants (Hymenoptera: Formicidae) in Budongo Forest. Uganda Oecologia 133:224-232

Santos MN (2016) Research on urban ants: approaches and gaps. Insect Soc 63:359-371

Seal JN, Kellner K, Trindl A, Heinze J (2011) Phylogeography of the parthenogenic ant Platythyrea punctata: highly successful colonization of the West Indies by a poor disperser. J Biogeogr 38:868-882

Skole D, Tucker D (1993) Tropical deforestation and habitat fragmentation in the Amazon: satellite data from 1978 to 1988 . Science 260: 1905-1910

Tews J, Brose U, Grimm V, Tielborgerm K, Wichmann MC, Schwager M, Jeltsch $F$ (2004) Animal species diversity driven by habitat heterogeneity/ diversity: the importance of keystone structures. J Biogeogr 31:79-92

Walter B, Brunner E, Heinze J (2011) Policing effectiveness depends on relatedness and group size. Am Nat 177:368-376

Yanoviak SP, Berghoff SM, Linsenmair KE, Zotz G (2012) Effects of an epiphytic orchid on arboreal ant community structure in Panama. Biotropica 43:731-737

Zmichorski M (2011) Does the decline of red wood ants after clearcutting favour epigeic arthropods? Eur J Entomol 108:425-430 